\title{
Significance of diet in treated and untreated acne vulgaris
}

\author{
Alicja Kucharska, Agnieszka Szmurło, Beata Sińska \\ Department of Human Nutrition, Faculty of Health Science, Medical University of Warsaw, Warsaw, Poland \\ Adv Dermatol Allergol 2016; XXXIII (2): 81-86 \\ DOI: 10.5114/ada.2016.59146
}

\begin{abstract}
The relationship between diet and acne is highly controversial. Several studies during the last decade have led dermatologists to reflect on a potential link between diet and acne. This article presents the latest findings on a potential impact that diet can have on pathogenesis of acne vulgaris. The association between diet and acne can no longer be dismissed. Compelling evidence shows that high glycemic load diets may exacerbate acne. Dairy ingestion appears to be weakly associated with acne and the roles of omega-3 fatty acids, dietary fiber, antioxidants, vitamin A, zinc and iodine remain to be elucidated. The question of what the impact of diet is on the course of acne vulgaris still remains unclear.
\end{abstract}

Key words: acne, diet, dairy, glycemic index, glycemic load, omega-3 fatty acids, zinc, vitamin A, iodine, dietary fiber.

\section{Introduction}

Acne vulgaris is a multifactorial dermatosis which occurs most often during puberty. Its pathogenesis is very complex and can be caused by many factors. The disease is characterized by seborrhea and formation of comedones, pustules and papules in areas rich in sebaceous glands $[1,2]$. There is a huge variety of clinical acne. There are patients who have only few blackheads and patients with the general skin involvement, with pustular deep lesions, abscesses and scarring, and, though it rarely occurs, even with the involvement of the joints, as in the case of acne fulminans. Acne vulgaris can occur in a few forms: acne comedonica, which is dominated by open and closed comedones, acne papulopustulosa, which is dominated by the inflammatory process and acne conglobata, which is the most severe form of acne and except the changes mentioned above, it is characterized with abscesses, fistulas and scars [3].

Acne vulgaris is one of the most commonly occurring skin conditions in the world. Relatively little is known about its epidemiology despite the fact that acne is almost a universal condition in younger people. The prevalence of the disease is difficult to estimate because lighter variants of acne are not presented to the dermatologists and are often cured with the use of domestic methods. This dermatosis is more common in developed countries than in less industrialized regions of the world. It is less common in African-Americans and Asians than in the Caucasian population. Acne lesions are present in almost all people at some period of their life. Acne may occur in prepubertal children (it is usually comedogenic), infants (it usually disappears after three months) and most frequently in the early teenage years, when production of sebum begins and first blackheads appear and can later turn into inflammatory lesions. Both women and men are affected by acne equally, however, a severe form often appears in men, probably due to the influence of hormones. During puberty everyone has more or less severe acne, which usually resolves spontaneously in early adulthood. Sometimes dermatosis lasts until the fourth decade of life or even during lifetime [4]. In large studies performed in the United States, France and Great Britain, acne is still among the first three most common skin diseases in the general population [4-6].

Acne vulgaris is a multifactorial dermatosis [1]. Nowadays it is shown that acne is caused by different factors such as increased production of sebum, the release of inflammatory mediators in the skin, hyperkeratosis and colonization by anaerobic Propionibacterium acnes (corynebacteria) [7]. Moreover, the factors contributing to the formation of acne also include genetic predispositions, hormonal abnormalities (androgens play the key role),

Address for correspondence: Alicja Kucharska MD, PhD, Department of Human Nutrition, Faculty of Health Science, Medical University of Warsaw, 27 Erazma Ciołka St, 01-445 Warsaw, Poland, phone: +48 2283609 71, 793444 661, e-mail: alicja.kucharska@wum.edu.pl Received: 7.08.2014, accepted: 23.09.2014. 
immunological disorders, psychological, environmental and even iatrogenic factors [8, 9]. It is believed that diet may play a role in pathogenesis of acne vulgaris and some products may have an effect on the course of this dermatosis [10].

\section{Aim of the study}

The role of diet in the course and treatment of acne vulgaris raises many questions and doubts, therefore the aim of the present study is to check and discuss the effects of selected dietary factors on the course of acne vulgaris. Those factors are milk and dairy products, chocolate, glycemic load of the diet, dietary fiber, fatty acids, antioxidants, zinc, vitamin A and iodine.

\section{Milk and dairy products}

The first studies on this issue have been conducted in the 40s of the last century, however until today there has been no conclusive evidence that milk and dairy products have comedogenic effects. The probable cause of possible comedogenic effects of milk and its products is the content of hormones produced by cows during pregnancy. It is believed that the constituent of milk that mostly stimulates the pilosebaceous unit is insulin-like growth factor 1 (IGF-1), whose concentration in the blood varies depending on the severity of acne [11]. Insulin-like growth factor 1 levels increase during puberty under the influence of the growth hormone and it positively correlates with the clinical course of acne. Receptors for IGF-1 are located in keratinocytes in the epidermis and are single, transmembrane receptors that are responsible for the tyrosine kinase activity. In acne patients, a positive correlation between concentrations of IGF-1, dehydroepiandrosterone sulfate, dihydrotestosterone, the number of acne lesions and sebum secretion was observed. Insulin-like growth factor 1 stimulates $5 \alpha$-reductase in adrenal glands and gonads, androgen synthesis, the androgen receptor signal transduction, sebocytes proliferation and lipogenesis [12]. The highest concentrations of IGF-1 are found in women with acne and the number of acne lesions positively correlates with the plasma levels of IGF-1 [12, 13]. High plasma levels of IGF-1 which are caused by consumption of milk, stimulates proliferation of sebocytes, resulting in the development and progression of acne lesions [13]. Decrease in fasting insulin and postprandial insulin and IGF-1 reduces the production of sebum and keratinocyte proliferation thereby reducing the number of acne lesions. Insulin-like growth factor 1 increases sensitivity of the adrenal gland to adrenocorticotropic hormone and induces the expression and activity of key enzymes involved in the biosynthesis of adrenal androgens [12]. Insulin-like growth factor 1 also stimulates the synthesis of androgens by ovaries and testicles and inhibits hepatic synthesis of sex hormone binding globulin (SHBG), which in effect increases bioavailability of androgens. Both IGF-1 and androgens stimulate sebum production, which is one of the pathogenic factors of acne formation [14].

Acne is influenced not only by hormones but also by the biochemical relationship between them and the pilosebaceous unit. Thus, adding exogenous hormones derived from the diet to the pool of endogenous hormones may have a significant impact. Milk that is available in stores is not only rich in placenta-derived progesterone but also other precursors of dihydrotestosterone (DHT), such as $5 \alpha$-pregnanedione and $5 \alpha$-androstanedione. These compounds are easily enzymatically modified to DHT and the enzymes required for this process are available in the pilosebaceous unit [15]. In vivo endogenous testosterone is converted via $5 \alpha$-reductase to $\mathrm{DHT}$, which stimulates the pilosebaceous unit. However, DHT can be produced without $5 \alpha$-reductase from exogenous $5 \alpha$-reduced molecules. Milk contains $5 \alpha$-reduced steroids, which are precursors of DHT. Both testosterone precursors and $5 \alpha$-reduced molecules are thought to contribute to the comedogenicity of milk. They work by stimulating production of sebum and inducing hyperkeratinization of the pilosebaceous unit [14]. Modified precursors enter the pilosebaceous unit and demonstrate a strong stimulating effect, for which humans are not evolutionary prepared. However steroid hormones contained in the milk are not the most important factor [15]. Many studies have shown that skim milk is more comedogenic than whole milk. It is believed that during the production of skim milk there are changes in the bioactivity of biologically active molecules such as glucocorticoids and transforming growth factor $\beta$ (TGF- $\beta$ ), hormones similar to thyrotropin and opiates and there are changes in their interactions with binding proteins. There is also a possibility that the hormonal balance of skim milk may be impaired. As a result, consumption of skim milk may cause increased comedogenesis. Moreover, in order to maintain the proper consistency of skim milk manufacturers add to it whey proteins, such as $\alpha$-lactoalbumin, which role in comedogenesis is also not negligible [16].

In 2005, Adebamowo et al. examined the alleged connection between milk and dairy consumption and acne in a cohort, retrospective study of almost 50 thousands women [17]. They were asked to recall their high school diet using a validated food frequency questionnaire. Subjects were also asked if they ever had physician-diagnosed severe acne. The authors found that acne was positively associated with a reported quantity of milk ingested, particularly skim milk. The authors speculated that bioavailability of comedogenic components may increase during manufacturing of skim milk. Skim milk contains less estrogen than whole milk. Estrogen is a hormone that may reduce acne. Adebamowo et al. also showed a positive correlation between acne and consumption of breakfast instant products and cottage cheese. It is an effect of cow's milk content in those products $[14,17]$. 
In 2006, Adebamowo et al. conducted another cohort, prospective 3-year observation study. It included more than 6,000 girls aged from 9 to 15 years. A positive correlation between the consumption of milk with different fat content and the occurrence of acne vulgaris was shown [14]. In 2008, Adebamowo et al. conducted a prospective study that included more than 4,000 boys. A positive correlation between consumption of skim milk and acne vulgaris was shown [18].

In another study of 44 patients with acne, a positive correlation between the occurrence of acne and an increased consumption of milk and ice cream was demonstrated [19].

\section{Chocolate}

Chocolate has always been considered as a factor that may contribute to exacerbation of acne, but there is a very limited amount of evidence supporting its negative impact on the skin. Dermatologists often observe that patients have new pimples a few days after ingestion of products containing chocolate [16].

In a study of Greek students aged 13-18 years, 66\% of respondents mentioned chocolate as an acne aggravating factor [20]. In Fulton et al. study, 30 teenage boys and 35 adult males participated. Subjects were divided into two groups. One group was ingesting chocolate bars that contained 10 times more cocoa than standard candy bars, while the second group was consuming a bar that did not contain cocoa. No difference in the composition of sebum between two groups was observed and thus no association between consumption of chocolate and aggravation of acne lesions was found. Similarly in a study by Anderson, researchers created two groups of patients, one of which was given daily chocolate. Only one third of respondents consuming chocolate have developed new pathological lesions. However the results were not conclusive because of the additional ingredients contained in bars eaten by subjects. Studies on the effect of chocolate on the skin condition are controversial and inaccurate because of additional ingredients (milk, sugar, etc.) in bars and other products [14]. In 2011, the "Journal of American Academy of Dermatology" published a study, in which subjects consumed chocolate. Significant changes in severity of acne occurred among respondents after a single ingestion of chocolate. This allowed the authors to hypothesize that chocolate can exacerbate acne lesions [21]. However there is no information about the type of chocolate consumed by subjects and the percentage of cocoa in consumed samples, which can influence results. Dark chocolate contains more antioxidants than milk chocolate, which would lead to conclusion that it may have much smaller comedogenic effects. However this issue still remains unclear. As to the question of whether chocolate aggravates acne lesions, there is still no clear answer [16, 21].

\section{Glycemic index}

It is believed that glycemic load and glycemic index of whole diet may participate in pathogenesis of acne vulgaris. The most vulnerable is consumption of products based on their high values. Diet based on products with a high glycemic index leads to hyperinsulinemia. Elevated insulin levels stimulate the secretion of androgens and cause an increased production of sebum, which plays a fundamental role in pathogenesis of acne vulgaris [16, 22]. Hyperinsulinemia affects the level of circulating IGF-1 and insulin-growth factor binding protein (IGFBP-3), which directly affect keratinocyte proliferation and apoptosis. In hyperinsulinemia, the level of IGF-1 increases whereas the level of IGFBP-3 decreases, what leads to an imbalance. As a result, keratinocyte proliferation increases. Insulin-like growth factor 1 influences comedogenic factors such as androgens, growth hormone and glucocorticoids. It has been shown that androgens increase the endogenous levels of IGF-1 in blood and this increases further level of androgens. A vicious circle is thus created in effect contributing to an increased production of sebum [17, 18, 23]. Studies on the effects of diet on acne vulgaris have shown that occurrence of acne is lower in rural and nonindustrialized areas than in Western populations [23]. It is believed that it may be a result of differences between glycemic loads of diets of both populations. In 2002, Cordain et al. conducted a study among two non-Western populations - the Kitavan Islanders of Papua New Guinea and the Aché hunter-gatherers of Paraguay. Among approximately 1300 subjects, no cases of acne were reported. Cordain et al. suggested that the absence of acne in these societies may have been a direct consequence of their diets [14, 24]. Both populations subsist on low glycemic load diets devoid of Western refined foods such as cereals, chips, cookies and bread [14]. The diet of the Kitavan people consisted of tubers, fruits, fish, and coconuts. Intake of dairy products, coffee, alcohol, cereal, sugar, oils and salt was minimal [20]. The diet of the Aché community included locally cultivated foods (69\%, including sweet manioc, peanuts, maize and rice), wild game (17\%), Western foods (8\%, containing mainly pasta, flour, sugar, yerba tea and bread), domestic meat (3\%) and gathered forest products (3\%) [14]. Researchers suggested that a low fat intake and low glycemic load diet may be the cause of acne absence in both populations [24]. In a further publication, in 2003, Cordain et al. demonstrated that diet-induced hyperinsulinemia leads to cascade of endocrine system responses which may affect development of acne through the action of androgens, IGF-1, IGFBP-3 and retinoid signaling pathways [25]. The authors emphasized the importance of diet leading to hyperinsulinemia and indicated that it may be a risk factor in the development of acne by affecting proliferation of epidermis in hair follicle, hyperkeratinization and androgen controlled sebum secretion. The study lacked a control group which would consume Western foods. Absence of acne in these populations could 
be conditioned by genetic and environmental factors [14] However an epidemiological study conducted by Schaefer in 1971, who studied native Inuit population living in northern Canada for almost 30 years [26] and subsequent Bendiner's reports [27] showed that in this population there was no case of acne when they lived and were fed in a traditional way [22]. It was only after introduction of Western habits, such as an increased consumption of sweet soda, beef, dairy products and processed foods, acne lesions were diagnosed in the Inuit population [20]. Similar conclusions were reached by Thiboutot and Strauss, who described a case of young women from Ireland. They claimed that they did not present any acne lesions until migration from rural areas of Ireland to the United States [28]. Another study highly important in this field is investigations conducted among inhabitants of rural areas of Kenya [29], Zambia [30] and Bantu in South Africa [31]. Researchers observed much fewer cases of acne in inhabitants of these areas than in people from these regions living in Great Britain and the United States. In a study conducted in a small Brazilian village - Purus Valley, among school children, acne vulgaris was detected in $2.7 \%$ of all respondents [32].

Kaymak et al. investigated the relationship between acne and glycemic load and index, insulin sensitivity and blood plasma levels of IGF-1 [33]. It has been demonstrated that in the serum of acne patients, higher IGF-1 levels and significantly lower IGFBP-3 levels occurred in comparison to healthy patients. Moreover, as assessed on the basis of an intake questionnaire, acne patient's diet had a significantly higher glycemic index than healthy patient's diet [20].

The exception to the finding, that high glycemic load diet may contribute to occurrence of acne, is dairy products. They have a relatively low glycemic index, but paradoxically they increase the IGF-1 level in blood plasma [20].

Results of studies mentioned above suggest that high glycemic index diet may have a significant effect on the occurrence of acne vulgaris.

\section{Dietary fiber}

There are no clinical studies that clearly illustrate the effect of dietary fiber intake on the course of acne vulgaris. In Kaufman study, in which patients with acne vulgaris consumed daily $30 \mathrm{~g}$ of high fiber breakfast cereal (13 g fiber/serving), a significant improvement in the skin condition was shown [34]. In Smith et al. study, after introduction of a low glycemic load diet, improvement in the skin condition was noticed. Researchers suggested that it could be an effect of large amounts of dietary fiber in this kind of diet [35].

\section{Fatty acids}

The ratio of omega- 6 to omega- 3 fatty acids resulting from diet is one of the factors that modulate the inflam- matory mechanism. A high intake of omega-3 fatty acids can inhibit the production of proinflammatory cytokines which can have a therapeutic effect on acne vulgaris [14]. Leukotriene B4 (LTB4) is widely known as a substance that regulates sebum production. Omega-3 fatty acids, and particularly eicosapentaenoic acid (EPA) derived from fish oils and $\gamma$-linolenic acid (GLA) which is a part of borage oil, inhibit conversion of arachidonic acid into LTB4. Every pilosebaceous unit has ability to produce pro-inflammatory substances, including LTB4, using substances that come from decomposition of fat originated from diet. Fish oil, especially EPA can inhibit production of LTB4 and prevent inflammatory processes, although researchers do not clearly report a beneficial impact of fish oil on acne vulgaris [36, 37]. Omega-3 fatty acids have ability to lower IGF-1 levels, which also suggests that they may have a beneficial effect in treatment of acne [14].

A study conducted in 1961 in North Carolina among over 1000 teenagers showed that people who consume large amounts of fish and seafood, have less symptoms of acne (blackheads, papules, pustules, oily skin) [38]. A small study of 5 patients, published in 2008, showed that among patients who consumed dietary supplements based on omega-3 fatty acids (it consisted of: EPA, selenium, zinc and chromium) a reduced number of acne lesions was observed [36].

\section{Antioxidants}

Reactive oxygen species produced by neutrophils participate in inflammatory progression of acne. Reactive oxygen species are normally removed by cellular antioxidants such as glucose-6-phosphate dehydrogenase and catalase, both of which are presented in small quantities in patients with acne. It has been suggested that oxidative stress may be implicated in the origin of acne and that drugs with antioxidant effects (or antioxidant supplements) may be valuable adjuvants in acne treatment [14].

In 2008, El-Akawi et al. conducted a study comparing blood levels of lipid-soluble antioxidants (vitamin A and $\mathrm{E}$ ) in 100 patients with acne and in 100 healthy control subjects without acne. They found that patients with acne had significantly lower plasma concentrations of these antioxidants as compared with the control subjects [39]. Low levels of blood selenium have also been documented in patients with acne. Because the selenium-dependent glutathione peroxidase enzyme activity is low in patients with acne, it is possible that selenium supplementation may be of value in acne [14]. In a study of 47 women and 42 men with acne vulgaris it has been shown that after 12-week supplementation of vitamin $E$ and selenium, the skin condition improved [40]. A study of hamsters has shown that catechins found in green tea inhibit sebum production [41] and that nobiletin, a flavonoid with antioxidant properties (which is found in the 
juice of Citrus depressa, popular in China and Japan), inhibits lipogenesis and proliferation of sebocytes and sebum production [42]. Resveratrol, a phytoalexin found in the skins of red grapes, red wine, peanuts and mulberries may be another promising antioxidant therapy for acne. In vitro, resveratrol has been shown to have bactericidal activity against Propionibacterium acnes, which plays an important role in the pathogenesis of acne [43].

Studies mentioned above are crucial to support the theory of the positive role of antioxidants in acne therapy, but effects of these substances in course of this disease are not yet fully explored.

\section{Zinc}

Zinc is a micronutrient that is essential for the development and functioning of the human skin. It has been shown to be bacteriostatic against Propionibacterium acnes, to inhibit chemotaxis and to reduce production of pro-inflammatory cytokine - tumor necrosis factor $\alpha$ (TNF- $\alpha$ ) [44].

In early studies on the influence of zinc on human skin conducted by Michaelsson and Fitzherbert in 1970's, it has been shown that acne improved with oral zinc supplementation in zinc-deficient patients $[45,46]$. Later studies have confirmed that patients with acne often are deficient in zinc $[47,48]$ and its oral supplementation has a positive effect on treatment of acne vulgaris [49-55]. However, the oral doses of zinc used in the majority of studies (400-600 mg zinc sulfate/day), were associated with nausea, vomiting and diarrhea [49, 50, 54, 56]. Gastrointestinal side effects can be reduced by consuming zinc directly after meals. Because zinc reduces absorption of copper, copper supplementation may be recommended in patients on chronic zinc therapy to prevent copper deficiency [14].

\section{Vitamin A}

Vitamin $A$ is a group of compounds which can be found in both animal and plant products. Retinol and its derivatives are found mainly in products of animal origin, while products of plant origin contain mainly provitamin A (carotenoids). Its main sources are milk and dairy products, eggs, liver, fish and oils derived from them. Vitamin A is a fat-soluble vitamin stored in the liver [57].

A study conducted in 1998 by Kligman et al. showed that oral supplementation of vitamin A (retinol) is effective in acne treatment when used in high doses (300 000 $\mathrm{U} /$ day for women and 400 000-500 $000 \mathrm{U} /$ day for men). The only observed side effects are xerosis and cheilitis [58].

\section{lodine}

lodine is a nutrient that is essential for the proper organism functioning. Acne that occurs after ingestion of foods rich in iodine appears suddenly and is characterized by many papules. It has been hypothesized that the association between acne and milk may be a result of the iodine content of milk which can vary with time of year, location, supplementation of animal feed and use of iodophor-sanitizing solutions [14].

\section{Summary}

The impact of diet on the course of acne vulgaris is still a very controversial subject, but can no longer be overlooked. Although the link between dairy intake and acne is less convincing than that between a high glycemic diet and acne, both deserve consideration when providing any dietary advice. The roles of antioxidants, omega-3 fatty acids, zinc, vitamin A, dietary fiber and iodine in the course of acne remain unclear. Despite all the results of the studies mentioned in the article, dermatologists will benefit by careful listening to their patients. If a patient notes an association between a particular dietary factor and acne severity, he should be instructed to exclude it from diet or limit its consumption. Doctors should encourage patients to write in a food diary which dietary factors produce acne flare-up. Influence of diet on severity of acne vulgaris still requires a lot of research but it should be no longer a dermatologic dogma to state that any association between diet and acne is a myth.

\section{Conflict of interest}

The authors declare no conflict of interest.

\section{References}

1. Webster G, Rawlings A. Trądzik. Diagnostyka i leczenie. Czelej, Lublin 2009.

2. Lucky AW, Biro FM, Huster GA, et al. Acne vulgaris in early adolescent boys: correlations with pubertal maturation and age. Arch Dermatol 1991; 127: 210-6.

3. Braun-Falco O, Plewig G, Wolff H, Winkelmann R. Dermatology. Springer-Verlag, Berlin, Heidelberg 1991.

4. Bhate K, Williams HC. Epidemiology of acne vulgaris. $\mathrm{Br}$ J Dermatol 2013; 168: 474-85.

5. Wolkenstein P, Grob JJ, Bastuji-Garin S, et al. French people and skin diseases: results of a survey using a representative sample. Arch Dermatol 2003; 139: 1614-9.

6. Johnson MT, Roberts J. Skin conditions and related need for medical care among persons 1-74 years. United States, 19711974. Vital Health Stat 11 1978; 212: i-v, 1-72.

7. Bergler-Czop B, Brzezińska-Wcisło L. Pro-inflammatory cytokines in patients with various kinds of acne treated with isotretinoin. Postep Derm Alergol 2014; 31: 21-8.

8. Biegalska J, Żaba R. Trądzik pospolity. Przeg Lek 2004; 6: 34-60.

9. Jakubowicz O, Jarmuda S, Żaba R, et al. Trądzik pospolity etiopatogeneza, obraz kliniczny i leczenie. Postep Derm Alergol 2012; 29 (Suppl. 2): 42-9.

10. Szyszkowska B, tepecka-Klusek C, Kozłowicz K, et al. The influence of selected ingredients of dietary supplements on skin condition. Postep Derm Alergol 2014; 31: 174-81. 
11. Danby FW. Acne and milk, the diet myth, and beyond. J Am Acad Dermatol 2005; 52: 360-2.

12. Arora M, Yadav A, Saini V. Role of hormones in acne vulgaris. Clin Biochem 2011; 44: 1035-40.

13. Melnik BC. Milk - the promoter of chronic Western diseases. Med Hypoth 2009; 72: 631-9.

14. Bowe WP, Joshi SS, Shalita AR. Diet and acne. J Am Acad Dermatol 2010; 63: 124-41.

15. Marcason W. Milk consumption and acne - is there a link? J Am Diet Assoc 2010; 110: 152

16. Adilson C, Thais Abdalla M. Acne and diet: truth or myth? An Bras Dermatol 2010; 85: 346-53.

17. Adebamawo CA, Spiegelman D, Danby FW, et al. High school dietary dairy intake and teenage acne. J Am Acad Dermatol 2005; 52: 207-14.

18. Adebamowo CA, Spiegelman D, Berkey CS, et al. Milk consumption and acne in teenaged boys. J Am Acad Dermatol 2008; 58: 787-93.

19. Ismail NH, Manaf ZA, Azizan NZ. High glycemic load diet, milk and ice cream consumption are related to acne vulgaris in Malaysian young adults: a case control study. BMC Dermatol 2012; 12: 13.

20. Spencer EH, Ferdowsian HR, Barnard ND. Diet and acne: a review of evidence. Int J Dermatol 2009; 48: 339-47.

21. Block SG, Valins WE, Caperton CV, et al. Exacerbation of facial acne vulgaris after consuming pure chocolate. J Am Acad Dermatol 2011; 65; e114-5.

22. Emiroğlu N, Cengiz FP, Kemeriz F. Insulin resistance in severe acne vulgaris. Postep Derm Alergol 2015; 32: 281-5.

23. Wolf R, Matz H, Orion E. Acne and diet. Clin Dermatol 2004; 22: 387-93.

24. Cordain L, Lindeberg S, Hurtado M, et al. Acne vulgaris: a disease of Western civilization. Arch Dermatol 2002; 138: 1584-90.

25. Cordain L, Eades MR, Eades MD. Hyperinsulinemic diseases of civilization: more than just syndrome X. Comp Biochem Physiol 2003; 136: 95-112.

26. Schaefer O. When the Eskimo comes to town. Nutr Today 1971; 6: 8-16.

27. Bendiner E. Disastrous trade-off: Eskimo health for white "civilization". Hosp Pract 1974; 9: 156-89.

28. Thiboutot D, Strauss J. Diet and acne revisited. Arch Dermatol 2002; 138: 1591-2.

29. Verhagen A, Koten J, Chaddah V, et al. Skin diseases in Kenya. A clinical and histopathological study of 3,168 patients. Arch Dermatol 1968; 98: 577-86.

30. Ratnam A, Jayaraju K. Skin disease in Zambia. Br J Dermatol 1979; 101: 449-53.

31. Park R. The age distribution of common skin disorders inthe Bantu of Pretoria, Transvaal. Br J Dermatol 1968; 80: 758-61.

32. Bechelli L, Haddad N, Pimenta W, et al. Epidemiological survey of skin diseases in schoolchildren living in the Purus Valley (Acre State, Amazonia, Brazil). Dermatologica 1981; 163: 78-93.

33. Kaymak Y, Adisen E, Itter N, et al. Dietary glycemic indexand glucose, insulin, insulin-like growth factor-I, insulin-likegrowth factor binding protein 3, and leptin levels in patients with acne. J Am Acad Dermatol 2007; 57: 819-23.

34. Kaufman WH. The diet and acne. Arch Dermatol 1983; 119: 276.

35. Smith RN, Mann NJ, Braue A, et al. A low-glycemic-load diet improves symptoms in acne vulgaris patients: a randomized controlled trial. Am J Clin Nutr 2007; 86: 107-15.
36. Rubin MG, Kim K, Logan AC. Acne vulgaris, mental health and omega-3 fatty acids: a report of cases. Lipids Health Dis 2008; 7: 36

37. Calder PC. Omega-3 fatty acids and inflammatory processes. Nutrients 2010; 2: 355-74.

38. Hitch JM, Greenburg BG. Adolescent acne and dietary iodine. Arch Dermatol 1961; 84: 898-911.

39. El-Akawi Z, Abdel-Latif N, Abdul-Razzak K. Does the plasma level of vitamins $A$ and $E$ affect acne condition? Clin Exp Dermatol 2006; 31: 430-4.

40. Michaelsson G, Edqvist LE. Erythrocyte glutathione peroxidase activity in acne vulgaris and the effect of selenium and vitamin E treatment. Acta Derm Venereol 1984; 64: 9-14.

41. Liao S. The medicinal action of androgens and green tea epigallocatechin gallate. Hong Kong Med J 2001; 7: 369-74.

42. Sato T, Takahashi A, Kojima M, et al. A citrus polymethoxy flavonoid, nobiletin inhibits sebum production and sebocyte proliferation, and augments sebum excretion in hamsters. J Invest Dermatol 2007; 127: 2740-8.

43. Docherty JJ, McEwen HA, Sweet TJ, et al. Resveratrol inhibition of Propionibacterium acnes. J Antimicrob Chemother 2007; 59: 1182-4.

44. Bowe WP, Shalita AR. Effective over-the-counter acne treatments. Semin Cutan Med Surg 2008; 27: 170-6.

45. Michaelsson G, Juhlin L, Ljunghall K. A double-blind study of the effect of zinc and oxytetracycline in acne vulgaris. $\mathrm{Br}$ J Dermatol 1977; 97: 561-6.

46. Fitzherbert JC. Zinc deficiency in acne vulgaris. Med J Aust 1977; 2: 685-6.

47. Amer M, Bahgat MR, Tosson Z, et al. Serum zinc in acne vulgaris. Int J Dermatol 1982; 21: 481-4.

48. Michaelsson G, Vahlquist A, Juhlin L. Serum zinc and retinolbinding protein in acne. Br J Dermatol 1977; 96: 283-6.

49. Dreno B, Amblard P, Agache P, et al. Low doses of zinc gluconate for inflammatory acne. Acta Derm Venereol 1989; 69: 541-3.

50.Goransson K, Liden S, Odsell L. Oral zinc in acne vulgaris: a clinical and methodological study. Acta Derm Venereol 1978; 58: 443-8.

51. Hillstrom L, Pettersson L, Hellbe L, et al. Comparison of oral treatment with zinc sulphate and placebo in acne vulgaris. Br J Dermatol 1977; 97: 681-4.

52. Liden S, Goransson K, Odsell L. Clinical evaluation in acne. Acta Derm Venereol Suppl (Stockh) 1980; 89 (Suppl.): 47-52.

53. Michaelsson G, Juhlin L, Vahlquist A. Effects of oral zinc and vitamin A in acne. Arch Dermatol 1977; 113: 31-6.

54. Verma KC, Saini AS, Dhamija SK. Oral zinc sulphate therapy in acne vulgaris: a double-blind trial. Acta Derm Venereol 1980; 60: 337-40.

55. Orris L, Shalita AR, Sibulkin D, et al. Oral zinc therapy of acne: absorption and clinical effect. Arch Dermatol 1978; 114: 1018-20.

56. Weimar VM, Puhl SC, Smith WH, tenBroeke JE. Zinc sulfate in acne vulgaris. Arch Dermatol 1978; 114: 1776-8.

57. Gawęcki J. Żywienie człowieka. Podstawy nauki o żywieniu. Wyd. Naukowe PWN, Warsaw 2012.

58. Kligman AM, Mills OH Jr, Leyden JJ, et al. Oral vitamin A in acne vulgaris: preliminary report. Int J Dermatol 1981; 20: 278-85. 